\title{
Calcium antagonism and reversibility of gentamicin-induced loss of cochlear microphonics in the guinea pig
}

\author{
Akira Takada and Jochen Schacht \\ Kresge Hearing Research Institute, University of Michigan, Ann A rbor, MI 48109, U.S.A.
}

(Received 2 April 1982; accepted 27 May 1982)

\begin{abstract}
The perilymphatic space of the guinea pig cochlea was perfused with various concentrations of $\mathrm{Ca}^{2+}$, $\mathrm{Mg}^{2+}$ and gentamicin. Cochlear microphonic potentials $(\mathrm{CM})$ were essentially stable when solutions contained $1 \mathrm{mM} \mathrm{Ca}{ }^{2+}$ plus $2 \mathrm{mM} \mathrm{Mg}^{2+}, 1 \mathrm{mM} \mathrm{Ca}^{2+}$ and no $\mathrm{Mg}^{2+}$ or when both $\mathrm{Ca}^{2+}$ and $\mathrm{Mg}^{2+}$ were omitted. In the absence of $\mathrm{Ca}^{2+}$, the presence of $2 \mathrm{mM} \mathrm{Mg}^{2+}$ or $1 \mathrm{mM}$ EGTA markedly decreased CM.

Addition of $3 \mathrm{mM}$ gentamicin lowered $\mathrm{CM}$, the magnitude of the effect depending on the concentration of $\mathrm{Ca}^{2+}$ present. Ten $\mathrm{mM} \mathrm{Ca}{ }^{2+}$ eliminated the action of the drug. In the absence of $\mathrm{Ca}^{2+}$, the effects of $\mathrm{Mg}^{2+}$ and gentamicin were additive.

When the application of gentamicin was followed by perfusion with drug-free medium, suppression of $\mathrm{CM}$ by $3 \mathrm{mM}$ drug could be reversed with $10 \mathrm{mM} \mathrm{Ca}^{2+}$ but not with $1 \mathrm{mM} \mathrm{Ca}^{2+}$. Loss of $\mathrm{CM}$ was irreversible when administration of $10 \mathrm{mM} \mathrm{Ca}^{2+}$ was delayed or when the drug concentration was increased to $10 \mathrm{mM}$.

The results are consistent with our previous hypothesis of a biphasic mechanism of aminoglycoside toxicity: an initial action competitive with calcium ions and reversible and a second step, non-competitive and irreversible.
\end{abstract}

Key words: cochlear microphonics; gentamicin; aminoglycoside ototoxicity; reversibility; calcium.

\section{Introduction}

Aminoglycoside antibiotics exert three major toxic actions on mammalian tissues: block of neuromuscular and ganglionic transmission [12], nephrotoxicity [5] and ototoxicity [2]. Each of these effects has its own characteristics and relationships between them are not readily apparent. Antagonism by calcium has been reported for the actions of aminoglycosides at neuromuscular and synaptic junctions [12,17] but not for nephro- and ototoxicity; neuromuscular block and renal damage are reversible while cochlear effects are irreversible and may even progress after cessation of drug treatment.

Studies in the lateral line organ, however, suggest that the ototoxic effects of aminoglycosides are influenced by cations and may be reversible under specific conditions. The suppression of microphonic output by low streptomycin concentrations was reversed by high $\left[\mathrm{K}^{+}\right]$while high drug concentrations acted irreversibly 
[19]; the effects of neomycin on afferent synchronization were somewhat mitigated by the addition of $20 \mathrm{mM} \mathrm{Ca}^{2+}[15]$; and calcium prevented the action of dihydrostreptomycin on extracellular receptor potentials and the afferent nerve response [7].

We have previously proposed a hypothesis of aminoglycoside toxicity based on in vivo and in vitro observations. It postulates a biphasic membrane action of the drugs [9,18]: aminoglycosides first displace membrane calcium in a step that is competitive with calcium and reversible; secondly, they specifically interact with the acidic phospholipid, phosphatidylinositol hisphosphate, a process non-competitive with $\mathrm{Ca}^{2+}$ and leading to irreversible membrane damage. While the details of this model were delineated primarily from in vitro drug-lipid interactions $[9,14]$ the hypothesis suggests a sequence of in vivo actions. The present study tests the reversibility and calcium antagonism of gentamicin-induced loss of cochlear microphonics in perilymphatic perfusions of the guinea pig cochlea.

\section{Materials and Methods}

Perilymphatic perfusions were carried out in male albino guinea pigs (200-400 g). Surgical and perfusion techniques were essentially as previously described $[8,11]$. An animal with a positive Preyer hearing reflex was anesthetized with pentobarbital ( 20 $\mathrm{mg} / \mathrm{kg}$ body wt., i.p.), atropine sulfate $(0.05 \mathrm{mg} / \mathrm{kg}$ body wt., s.c.) and Innovar $(0.5$ $\mathrm{ml} / \mathrm{kg}$ body wt., i.m. containing $0.4 \mathrm{mg}$ fentanyl and $20.0 \mathrm{mg}$ droperidol $/ \mathrm{ml}$ ). Body temperature was maintained at $37 \pm 1{ }^{\circ} \mathrm{C}$ with a heating pad and artificial respiration provided through a tracheal cannula.

Glass capillaries were implanted into the basal turn of scala tympani and scala vestibuli. Cochlear microphonic potentials $(\mathrm{CM})$ were measured from an electrode in one of the capillaries in response to a sound stimulus of white noise, $20-4000 \mathrm{~Hz}$, delivered through an earphone. The sound intensity was adjusted to approximately $70 \mathrm{~dB}$ SPL to give an initial CM of $200-400 \mu \mathrm{V}$ (RMS). Perilymphatic spaces were perfused at a rate of approximately $30 \mu \mathrm{l} / \mathrm{min}$ with artificial perilymph containing

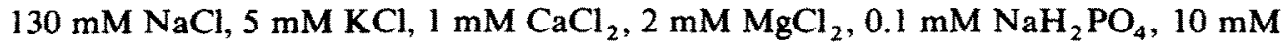
$\mathrm{NaHCO}_{3}, 5 \mathrm{mM}$ glucose and $10 \mathrm{mM}$ Hepes, final $\mathrm{pH}, 7.4$. After $\mathrm{CM}$ had stabilized for $30 \mathrm{~min}$ the 'control perfusate' was switched to the 'experimental perfusate' containing the drug and the perfusion continued. Experiments were usually carried out for 90-120 min but perfusions without drugs could be extended for up to $3 \mathrm{~h}$ without major $(<20 \%)$ loss of $\mathrm{CM}$. Animals with an initial $\mathrm{CM}$ of less than $200 \mu \mathrm{V}$ or with an unstable $\mathrm{CM}$ during the control period (loss of $>10 \%$ ) were eliminated from the study.

Results are expressed as initial rate of loss of $\mathrm{CM}(\% / \mathrm{min})$ as well as the absolute loss after $30 \mathrm{~min}$ of drug perfusion. These two measurements, while yielding essentially similar results, are not identical. The rate of loss, particularly at high drug concentrations, is not necessarily linear for $30 \mathrm{~min}$. Input-output functions of $\mathbf{C M}$ before and after perfusion of gentamicin showed that measurements at the chosen 
fixed intensity were representative of the drug-induced CM loss.

Gentamicin sulfate was a gift from the Schering Corp. (Bloomfield, N.J.).

\section{Results}

Prior to testing the aminoglycoside, the effects of the divalent cations $\mathrm{Ca}^{2+}$ and $\mathrm{Mg}^{2+}$ in the artificial perilymph were investigated (Table I). In the presence of both $1 \mathrm{mM} \mathrm{Ca}^{2+}$ and $2 \mathrm{mM} \mathrm{Mg}^{2+}, \mathrm{CM}$ was essentially stable over the experimental period. Neither the omission of $\mathrm{Mg}^{2+}$ nor the simultaneous omission of $\mathrm{Ca}^{2+}$ and $\mathrm{Mg}^{2+}$ had significant effects. However, when $\mathrm{Ca}^{2+}$ was absent from the medium, the presence of $\mathrm{Mg}^{2+}$ or $1 \mathrm{mM}$ EGTA led to a marked decrease of $\mathrm{CM}$. While the actions of $\mathrm{Mg}^{2+}$ and gentamicin (see below) were apparent within a few minutes after reaching the cochlea (delay 3-7 min), the onset of EGTA action was highly variable (delay 6-52 min). Therefore, the apparent loss at $30 \mathrm{~min}$ is not a meaningful measure in this case.

The addition of $3 \mathrm{mM}$ gentamicin to the perfusate lowered CM significantly (Fig. 1 and Table II). The magnitude of the effect was clearly dependent on the concentration of $\mathrm{Ca}^{2+}$ present, being highest in the absence of $\mathrm{Ca}^{2+} .10 \mathrm{mM} \mathrm{Ca}^{2+}$ eliminated the action of gentamicin: a short, initial loss of $\mathrm{CM}$ did not persist and $\mathrm{CM}$ recovered to reach essentially control values (Fig. 1). In contrast to the action of $\mathrm{Ca}^{2+}, \mathrm{Mg}^{2+}$ did not antagonize the aminoglycoside action. In the absence of calcium, effects of $\mathrm{Mg}^{2+}$ and drug were additive.

\section{TABLE I}

\section{EFFECT OF DIVALENT CATIONS ON COCHLEAR MICROPHONICS}

Perilymphatic perfusions were carried out as described in Materials and Methods. Control perfusate (1 $\mathrm{mM} \mathrm{Ca}{ }^{2+}, 2 \mathrm{mM} \mathrm{Mg}^{++}$) was perfused during a 30 min period directly preceding the application of the experimental perfusate. Rate of loss $(\% / \mathrm{min})$ is initial rate; $\% \mathrm{CM}$ lost at $30 \mathrm{~min}$ refers to time after application of experimental medium (see Materials and Methods). Numbers are means $\pm S$.D., with number of animals $(n)$ given in the last column.

\begin{tabular}{|c|c|c|c|c|c|}
\hline \multirow{2}{*}{\multicolumn{2}{|c|}{$\begin{array}{l}\text { Ion concentrations } \\
\text { in experimental } \\
\text { perfusate (mM) }\end{array}$}} & \multicolumn{2}{|c|}{ Loss of $\mathrm{CM}(\% / \mathrm{min})$ during } & \multirow{3}{*}{$\begin{array}{l}\text { CM lost } \\
\text { at } 30 \mathrm{~min} \\
(\%)\end{array}$} & \multirow[t]{3}{*}{$n$} \\
\hline & & \multirow{2}{*}{$\begin{array}{l}\text { Control } \\
\text { perfusion }\end{array}$} & \multirow{2}{*}{$\begin{array}{l}\text { Experimental } \\
\text { perfusion }\end{array}$} & & \\
\hline$\overline{\mathrm{Ca}^{2+}}$ & $\mathrm{Mg}^{2+}$ & & & & \\
\hline 1 & 2 & $0.08 \pm 0.10$ & $0.16 \pm 0.12$ & $3 \pm 3$ & 8 \\
\hline 1 & 0 & $0.06 \pm 0.05$ & $-0.28 \pm 0.37$ & $1 \pm 4$ & 5 \\
\hline 0 & 0 & $0.11 \pm 0.10$ & $0.10 \pm 0.09$ & $2 \pm 2$ & 10 \\
\hline 0 & 2 & $0.05=0.04$ & $1.02 \pm 0.62$ * & $26 \pm 13 *$ & 9 \\
\hline 0 & 0 & & & & \\
\hline \multicolumn{2}{|c|}{ + 1 mM EGTA } & $0.09 \pm 0.07$ & $3.57 \pm 1.28$ * & $* *$ & 6 \\
\hline
\end{tabular}

* Differs from control perfusate (paired $t$-test): $P<0.01$.

** Variable delay of effect $(6-52 \mathrm{~min})$. 
For the study of reversibility of gentamicin-induced loss of C.M, the drug was first administered with regular artificial perilymph containing $1 \mathrm{mM} \mathrm{Ca}^{2+}$ and $2 \mathrm{mM}$ $\mathrm{Mg}^{2+}$ (Fig. 2, point A). After an initial controlled loss of $\mathrm{CM}$, drug-containing

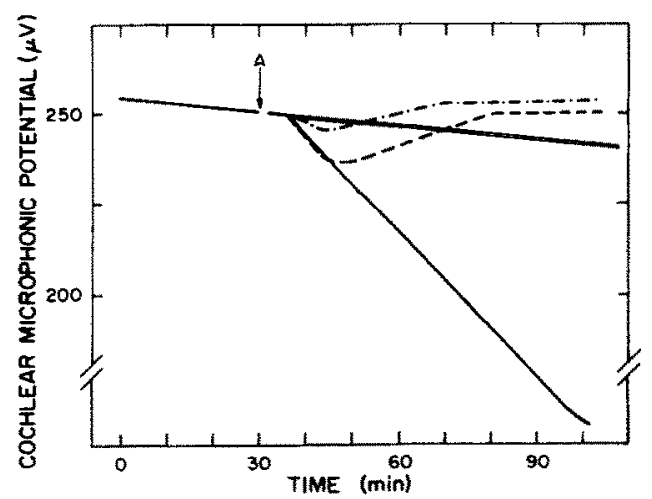

Fig. 1. Time course of gentamicin and calcium action on cochlear microphonic potentials. Perilymphatic perfusions were carried out as described in Materials and Methods. Following the control perfusion ('stabilizing period', 0-30 min), the perfusate was changed at point $A$ to experimental perfusate containing artificial perilymph with the following variations: =, no additions;,$- 3 \mathrm{mM}$ gentamicin; $-\cdots, 3 \mathrm{mM}$ gentamicin and $10 \mathrm{mM} \mathrm{CaCl}_{2} ; \cdots, 10 \mathrm{mM} \mathrm{CaCl}_{2}$. Note that 'artificial perilymph' always contains $1 \mathrm{mM}$ $\mathrm{CaCl}_{2}$. Curves show typical experimental results.

\section{TABLE II}

\section{EFFECT ON GENTAMICIN TOXICITY OF SIMULTANEOUSLY APPLIED Ca ${ }^{2+}$ AND $\mathrm{Mg}^{2+}$}

Perilymphatic perfusions were carried out as described in Materials and Methods. Control perfusate ( 1 $\mathrm{mM} \mathrm{Ca}{ }^{2+}, 2 \mathrm{mM} \mathrm{Mg}{ }^{2+}$ ) was perfused for $30 \mathrm{~min}$ preceding the application of the experimental perfusate. Rate of loss $(\% / \mathrm{min})$ is initial rate; $\% \mathrm{CM}$ lost at $30 \mathrm{~min}$ refers to time after application of experimental medium (see Materials and Methods). Numbers are means \pm S.D., with numbers of animals ( $n$ ) given in last column.

\begin{tabular}{|c|c|c|c|c|c|c|}
\hline \multicolumn{3}{|c|}{$\begin{array}{l}\text { Concentrations in } \\
\text { experimental perfusate (mM) }\end{array}$} & \multicolumn{2}{|c|}{ Loss of $\mathrm{CM}(\% / \mathrm{min})$ during } & \multirow{2}{*}{$\begin{array}{l}C M \text { lost } \\
\text { at } 30 \mathrm{~min} \\
(\%)\end{array}$} & \multirow[t]{2}{*}{$\mathbf{n}$} \\
\hline Gentamicin & $\mathrm{Ca}^{2+}$ & $\mathrm{Mg}^{2+}$ & $\begin{array}{l}\text { Control } \\
\text { perfusion }\end{array}$ & $\begin{array}{l}\text { Experimental } \\
\text { perfusion }\end{array}$ & & \\
\hline 3 & 1 & 2 & $0.08 \pm 0.11$ & $0.56 \pm 0.16 *$ & $14 \pm 5^{*}$ & 7 \\
\hline 3 & 0 & 0 & $0.06 \pm 0.08$ & $1.21 \pm 0.62 *$ & $24 \pm 11 *$ & 11 \\
\hline 3 & 10 & 2 & $0.07 \pm 0.06$ & $0.58 \pm 0.17 *$ & $3 \pm 2$ & 6 \\
\hline 3 & 1 & 0 & $0.08 \pm 0.07$ & $0.50 \pm 0.18 *$ & $10 \pm 6^{*}$ & 8 \\
\hline 3 & 0 & 2 & $0.05 \pm 0.09$ & $2.86 \pm 1.25 * *$ & $46 \pm 11 *$ & 4 \\
\hline 0 & 10 & 2 & $0.05 \pm 0.08$ & $0.12 \pm 0.20$ & $1 \pm 6$ & 7 \\
\hline
\end{tabular}

* Differs from control (paired $t$-test): $P<0.01$.

$* * P=0.02$. 


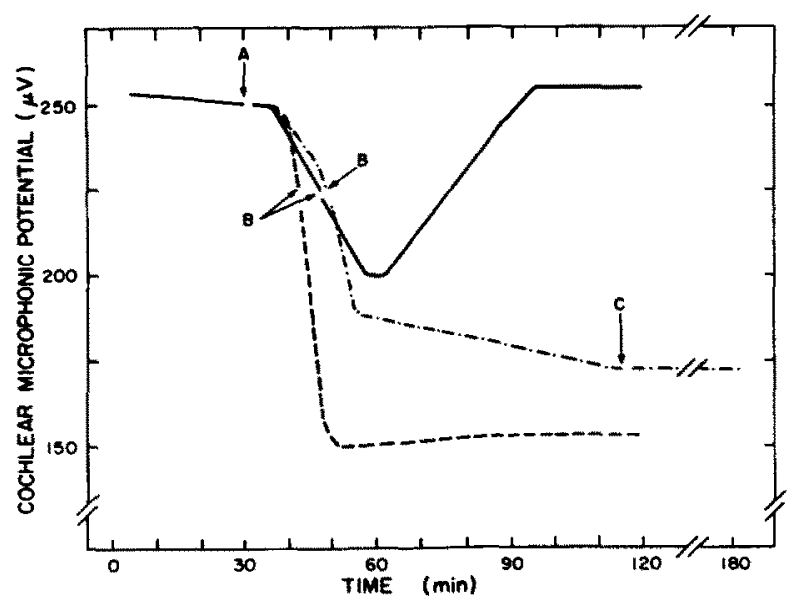

Fig. 2. Reversibility of gentamicin-induced suppression of cochlear microphonic potentials. Perilymphatic perfusions were carried out as described in Materials and Methods. Following the control perfusion (0-30 $\mathrm{min}$ ), the perfusate was changed a first time at point $A$ to experimental perfusate containing gentamicin, a second time at point $B$ to wash perfusate without drug; in one series of experiments, a third change was made at point $C$. The variations of artificial perilymph were:,$- 3 \mathrm{mM}$ gentamicin at $\mathrm{A}, 10 \mathrm{mM} \mathrm{CaCl}{ }_{2}$ at B; $\cdots 3 \mathrm{mM}$ gentamicin at $A$, no additions at $B, 10 \mathrm{mM} \mathrm{CaCl}_{2}$ at $\mathrm{C}:-\cdots, 10 \mathrm{mM}$ gentamicin at $\mathrm{A}, 10$ $\mathrm{mM} \mathrm{CaCl}$ at $\mathrm{B}$. Note that 'artificial perilymph' always contains $1 \mathrm{mM} \mathrm{CaCl}$. Curves show typical experimental results.

\section{TABLE III}

\section{REVERSIBILITY OF LOSS OF COCHLEAR MICROPHONICS}

Cochlear perfusions were carried out as described in Materials and Methods, and Results. Control perfusate ( $1 \mathrm{mM} \mathrm{Ca}^{2+}, 2 \mathrm{mM} \mathrm{Mg}^{2+}$ ) was perfused for $30 \mathrm{~min}$, followed by perfusion with experimental medium (see also Fig. 2, point A) which was subsequently exchanged for the 'wash' perfusate (Fig. 2, point B). Rate of loss (\%/min) refers to initial rate (see Materials and Methods); minimum of CM refers to the minimum of $\mathrm{CM}$ during the experiment before reversal of slope. When no minimum was apparent (i.e. no recovery under the conditions $3 \mathrm{mM} \mathrm{Gm} / 1 \mathrm{mM} \mathrm{Ca}{ }^{2+}$ or $10 \mathrm{mM} \mathrm{Gm}$ ) the value refers to $\mathrm{CM}$ at the change of slope induced by the wash. Numbers are means \pm S.D., with number of animals given $(n)$ in the last column.

\begin{tabular}{|c|c|c|c|c|c|c|}
\hline \multirow{2}{*}{$\begin{array}{l}\text { Additions to } \\
\text { experimental } \\
\text { perfusate ( } \mathrm{mM} \text { ) }\end{array}$} & \multirow{2}{*}{$\begin{array}{l}{\left[\mathrm{Ca}^{2+}\right] \text { in }} \\
\text { wash } \\
\text { perfusate } \\
(\mathrm{mM})\end{array}$} & \multicolumn{2}{|c|}{ Loss of $\mathrm{CM}(\% / \mathrm{min})$ during } & \multirow{2}{*}{$\begin{array}{l}\text { Minimum } \\
\text { of } \mathrm{CM} \\
\text { ( } \% \text { of } \\
\text { control) }\end{array}$} & \multirow{2}{*}{$\begin{array}{l}\mathrm{CM} \text { after } \\
1 \mathrm{hr} \text { wash } \\
\text { ( } \% \text { of control) }\end{array}$} & \multirow[t]{2}{*}{$n$} \\
\hline & & $\begin{array}{l}\text { Control } \\
\text { perfusion }\end{array}$ & $\begin{array}{l}\text { Experimental } \\
\text { perfusion }\end{array}$ & & & \\
\hline $\mathrm{Gm}, 3$ & 1 & $0.10 \pm 0.05$ & $1.02 \pm 0.33 *$ & $75 \pm 5$ & $71 \pm 17$ & 5 \\
\hline None & 10 & $0.08 \pm 0.03$ & $0.09 \pm 0.10$ & $98 \pm 1$ & $101 \pm 9$ & 5 \\
\hline $\mathrm{Gm}, 3$ & 10 & $0.11 \pm 0.05$ & $0.92=0.18^{*}$ & $80 \pm 3$ & $104 \pm 4^{* *}$ & 5 \\
\hline $\mathrm{Gm}, 10$ & 10 & $0.06 \pm 0.03$ & $4.20 \pm 1.27^{*}$ & $60 \pm 10$ & $58 \pm 18$ & 4 \\
\hline $\mathrm{Mg}^{2+}, 10$ & 10 & $0.09 \pm 0.05$ & $1.46=0.57 *$ & $72 \pm 3$ & $86 \pm 16 * * *$ & 7 \\
\hline EGTA, 1 & 10 & $0.07 \pm 0.07$ & $1.31 \pm 0.43^{*}$ & $81=6$ & $90 \pm 10 * *$ & 7 \\
\hline
\end{tabular}

- Differs from control (paired $t$-test): $P<0.01$.

* Differs from minimum CM: $P<0.01$.

*** Differs from minimum CM: $P=0.035$. 
'experimental perfusate' was exchanged for a drug-free 'wash perfusate' with varying calcium concentrations (Fig. 2, point B). When gentamicin was administered at 3 $\mathrm{mM}$, followed by wash perfusate with $1 \mathrm{mM} \mathrm{Ca}^{2+}$, loss of $\mathrm{CM}$ continued after elimination of the drug from the cochlea, albeit a change to a lesser loss per min after $5 \mathrm{~min}$ (Fig. 2, Table III); final subsequent perfusion with $10 \mathrm{mM} \mathrm{Ca}{ }^{2+}$ in perilymph (Fig. 2, point $C$ ) did not recover $C M$. In contrast, when $10 \mathrm{mM} \mathrm{Ca}{ }^{2+}$ was perfused immediately following $3 \mathrm{mM}$ gentamicin (Fig. 2, point B) CM recovered to control values within about $40 \mathrm{~min}$. Such reversibility by $10 \mathrm{mM} \mathrm{Ca}^{2+}$ was not observed when the initial drug concentration was raised to $10 \mathrm{mM}$ gentamicin. The detrimental effects of $10 \mathrm{mM} \mathrm{Mg}{ }^{2+}$ or $1 \mathrm{mM}$ EGTA on CM could be reversed, at least partially, by $10 \mathrm{mM} \mathrm{Ca}^{2+}$ (Table III).

\section{Discussion}

The cochlear microphonic potential is a sensitive indicator of noxious influences on the cochlea including damage by aminoglycosides [3]. While the origins and functions of this a.c. potential remain obscure, it is well characterized in its dependence on the ionic milieu of the inner ear fluids. The requirement for calcium ions [6] is supported in this study and it is evident that the endogenous pool of calcium is under strict homeostatic control. Excess $\mathrm{Ca}^{2+}$ in perilymphatic perfusions raises $C M$ [10] while endolymphatic application lowers $C M$ [16]. The endogenous $\mathrm{Ca}^{2+}$ is also not easily exchangeable. The absence of calcium from the perfusion medium does not adversely affect $\mathrm{CM}$ unless magnesium ion or the calcium chelator EGTA are present. Magnesium appears to act in a competitive manner as the ratio of $\mathrm{Ca}^{2+}: \mathrm{Mg}^{2+}$ determines the effect on the CM. This is in good agreement with studies on the lateral line organ of the mudpuppy [13]. Furthermore, CM depressed by magnesium recovers with subsequent administration of calcium indicating the reversibility of its action.

Calcium antagonism and reversibility of aminoglycoside ototoxicity, on the other hand, appear to be complex phenomena. Wersäll and Flock [19] reported that in the lateral line organ, high $\mathrm{K}^{+}$reversed the effect of streptomycin on the microphonic output, provided the drug concentrations remained low. Shiozawa [15] found simultaneous administration of $\mathrm{Ca}^{2+}$ rather than $\mathrm{K}^{+}$effective in restoring adverse neomycin effects. In contrast to the results from the lateral line organ, aminoglycoside actions in the mammalian ear are generally considered irreversible.

The complexity of the problem and a possible explanation for the apparently discrepant behavior of the lateral line and cochlea can be seen in our studies. Calcium antagonism and reversibility of ototoxicity are limited to a narrow range of conditions with regard to both concentration and duration of drug exposure.

It is evident that effects caused by low concentrations of gentamicin and short treatment are readily antagonized by $\mathrm{Ca}^{2+}$. This is first apparent in the simultaneous application of $\mathrm{Ca}^{2+}$ to the perfusate containing $3 \mathrm{mM}$ gentamicin. The calcium-dependent restoration of $\mathrm{CM}$ is consistent with a competitive action of the 
two compounds which we previously observed in natural and artificial membranes $[9,14,18]$.

Secondly, a perfusion with $10 \mathrm{mM} \mathrm{Ca}{ }^{2+}$ is effective in restoring $\mathrm{CM}$ if directly applied after exposure of the cochlea to $3 \mathrm{mM}$ gentamicin. However, after longer exposures or higher concentrations of the drug, reversibility can no longer be observed. High calcium $(10 \mathrm{mM})$ failed to reverse the drug effect when its application was delayed by $60 \mathrm{~min}$, although the cochlea was washed free of excess drug during this time by artificial perilymph containing $1 \mathrm{mM} \mathrm{Ca}^{2+}$. Similarly, calcium antagonism is no longer observed when gentamicin is raised to $10 \mathrm{mM}$.

Our demonstration of the biphasic ototoxic action of gentamicin has both theoretical and clinical implications. It is clearly consistent with and supports our previous hypothesis of a two-step or biphasic action of aminoglycosides. The initial displacement of calcium and concomitant inhibition of membrane function are reversible. The second step, postulated to be a specific interaction with a receptor like phosphatidylinositol bisphosphate, is non-competitive with $\mathrm{Ca}^{2+}$ and essentially irreversible [14].

Of potential clinical importance is the observation that aminoglycoside ototoxicity is initially reversible. In practice, however, means to manipulate calcium levels in the inner ear are limited. Juhn reported [4] only transiently increased perilymphatic $\mathrm{Ca}^{2+}$ following hypercalcemia induced by $\mathrm{CaCl}_{2}$ injections in chinchillas. Generally, cochlear calcium concentrations follow serum concentrations which are under homeostatic control. Increased calcium loads are efficiently excreted by the kidney. Also, it has to be considered that an antagonism by calcium will not only be directed against the toxic effects of aminoglycosides but also against their antibacterial efficacy [1].

Drug concentrations in these model studies are higher than those expected in the cochlea after application of clinically relevant doses $(0.01-0.1 \mathrm{mM}$, Tran Ba Huy and Schacht, in preparation). The fact that $1 \mathrm{mM} \mathrm{Ca}^{2+}$, the approximate concentration in serum and perilymph, is rather ineffective in suppressing aminoglycoside damage in perfusions should therefore not lead to false conclusions. Physiological concentrations of calcium may well be effective antagonists of aminoglycosides in vivo until time of exposure or concentration of drug reach a certain limit. It would be of interest to determine this limit in vivo.

In summary, our study shows that initial gentamicin actions on the guinea pig cochlea are reversible by calcium, similarly to those at the neuromuscular junction and kidney. Depending on duration and concentration of the drug, irreversible damage will follow in the cochlea.

\section{Acknowledgement}

This research was supported by research grant NS-13792 and Program Project grant NS-05785 from the National Institutes of Health. 


\section{References}

1 Hancock, R.E.W. (1981): Aminoglycoside uptake and mode of action - with special reference to streptomycin and gentamicin. I. Antagonists and mutants. J. Antimicrob. Chemother. 8, 249-276.

2 Hawkins, J.E. Jr. (1970): Biochemical aspects of ototoxicity. In: Biochemical Mechanisms in Hearing and Deafness, pp. 323-339. Editor: M.M. Paparella. Charles C. Thomas, Springfield, Ill.

3 Hawkins, J.E. Jr. (1976): Drug ototoxicity. In: Handbook of Sensory Physiology. pp. 707-748. Editors: W.D. Keidel and W.D. Neff. Springer-Verlag, Berlin.

4 Juhn, S.K. and Youngs, J.N. (1976): The effect on perilymph of the alteration of serum glucose or calcium concentration. Laryngoscope 86, 273-279.

5 Kaloyanides, G.J. and Pastoriza-Munoz, E. (1980): Aminoglycoside nephrotoxicity. Kidney Int. 18, 571-582.

6 Konishi, T. and Kelsey, E. (1970): Effect of calcium deficiency on cochlear potentials. J. Acoust. Soc. Am. 47, 1055-1062.

7 Kroese, A.B.A and van den Bercken, J. (1982): Effects of ototoxic antibiotics on sensory hair cell functioning. Hearing Res. 6, 183-197.

8 Lodhi, S., Weiner, N.D., Mechigian, I. and Schacht, J. (1980): Ototoxicity of aminoglycosides correlated with their action on monomolecular films of polyphosphoinositides. Biochem. Pharmacol. 29, 597-601.

9 Lodhi, S., Weiner, N.D. and Schacht, J. (1979): Interactions of neomycin with monomolecular films of polyphosphoinositides and other lipids. Biochim. Biophys. Acta 557, 1-8.

10 Moscovitch, D.H. and Gannon, R.P. (1966): Effects of calcium on sound-evoked cochlear potentials in the guinea pig. J. Acoust. Soc. Am. 40, 583-590.

11 Nuttall, A.L., LaRouere, M.J. and Lawrence, M. (1982): Acute perilymphatic perfusion of the guinea pig cochlea. Hearing Res. 6, 207-221.

12 Pittinger, C. and Adamson, R. (1972): Antibiotic blockage of neuromuscular function. Annu. Rev. Pharmacol. 12, 169-184.

13 Sand, O. (1975): Effects of different ionic environments on the mechanosensitivity of lateral line organs in the mudpuppy. J. Comp. Physiol. 102, $27-42$.

14 Schacht, J., Lodhi, S. and Weiner, N.D. (1977): Effects of neomycin on polyphosphoinositides in inner ear tissues and monomolecular films. In: Membrane Toxicity, pp. 191-208. Editors: M.W. Miller and A.E. Shamoo. Plenum Press, New York.

15 Shiozawa, K. and Yanagisawa, K. (1979): Effects of neomycin on the lateral-line organ of the mudpuppy. Proc. Jap. Acad. Ser. B 55, 374-379.

16 Tanaka, Y., Asanuma, A. and Yanagisawa, K. (1980): Potentials of outer hair cells and their membrane properties in cationic environments. Hearing Res. 2, 431-438.

17 Vital Brazil, O. and Prado-Franceschi, J. (1969): The nature of neuromuscular block produced by neomycin and gentamicin. Arch. Int. Pharmacodyn. Therap. 179, 78-85.

18 Weiner, N.D. and Schacht, J. (1981): Biochemical model of aminoglycoside-induced hearing loss. In: Aminoglycoside Ototoxicity, pp. 113-124. Editors: S.A. Lerner, G.J. Matz and J.E. Hawkins, Jr. Little, Brown and Co., Boston.

19 Wersäll, J. and Flock, $\dot{A}$. (1964): Suppression and restoration of the microphonic output from the lateral line organ after local application of streptomycin. Life Sci. 3, 1151-1155. 